\author{
Kathryn Puxty \\ Philip McLoone \\ Tara Quasim \\ John Kinsella \\ David Morrison
}

\section{Survival in solid cancer patients following intensive care unit admission}

Received: 9 February 2014

Accepted: 26 August 2014

Published online: 16 September 2014

(C) Springer-Verlag Berlin Heidelberg and

ESICM 2014

Electronic supplementary material

The online version of this article (doi:10.1007/s00134-014-3471-9) contains supplementary material, which is available to authorized users.

K. Puxty

NHS Greater Glasgow and Clyde, Glasgow, Scotland, UK

\section{P. McLoone · D. Morrison}

West of Scotland Cancer Surveillance Unit, Institute of Health and Wellbeing,

University of Glasgow, Glasgow, Scotland, UK

K. Puxty (®) - T. Quasim - J. Kinsella Department of Anaesthesia, Pain and Critical Care, University of Glasgow,
Glasgow Royal Infirmary, Castle Street, Glasgow G4 0SF, Scotland, UK e-mail:kadunne@doctors.net.uk kadunne@doctors.org.uk Tel.: +44 1412018630
Abstract Purpose: One in seven patients admitted to intensive care units (ICU) has a cancer diagnosis but evidence on their expected outcomes after admission has not been syn- thesised. Methods: Systematic literature review of solid cancer adult patients admitted to ICU from 2000 onwards using EMBASE and MED- LINE electronic databases.
Results: There were 48 papers identified that reported survival in ICU patients with solid cancers. ICU mortality was reported in 35 studies comprising a total sample of 25,339 patients and ranging from 4.5 to $85 \%$. The average mortality of the distribution of reported mortality

rates within ICU was $31.2 \%$ (95\% CI 24.0-39.0 \%). Hospital mortality was reported in 31 studies across a total sample of 74,061 patients. The average hospital mortality was $38.2 \%(33.8-42.7 \%)$ and ranged from 4.6 to $76.8 \%$. Poorer physiological score, invasive mechanical ventilation and poor functional status were associated with higher mortality. Conclusions: Several factors have been associated with poor survival in ICU cancer patients; however, primary research is still needed to describe outcomes in cancer patients with sufficient case mix and treatment details to be of prognostic value to clinicians.

Keywords Cancer - Intensive care Critical illness $\cdot$ Co-morbidity

\section{Introduction}

Advances in oncology have led to a dramatic reduction in mortality rates in cancer patients over the past few decades [1]. However, this has come at the cost of using more complex and intensive cytotoxic and immunosuppressive regimens, in addition to undertaking major surgical procedures in patients who would previously received palliative care. As a result, there is an increasing demand for critical care input to support patients through these therapies or the complications that arise as a consequence.
Around one in seven patients admitted to general intensive care units (ICU) in Europe have a malignancy, the majority being solid tumours [2]. Multiple organ support can be offered but the burden of treatment can be significant for patients and therefore it is only undertaken when there is a reasonable expectation of survival [3]. Much of the controversy regarding ICU care of cancer patients surrounds expected survival in this group of patients. It may not always be appropriate to provide intensive care and organ support to patients with a reversible illness but an otherwise terminal process. In 
cancer patients, there are increasing questions about whether too much effort is made to prolong life at the cost of poorer quality in the last few months of life. For those patients approaching the end of their life, it has been recognised that care should be less medicalised and occur outside the hospital environment [4].

Due to these concerns, the presence of cancer is the second most common reason cited by intensive care physicians for refusal of ICU admission [5]. However, there may be a cohort of cancer patients who would benefit from an ICU admission but are refused on the basis of prejudices against this patient population. Cancer is one of many chronic comorbid conditions that are common in the ICU population. It is likely that the presence of chronic conditions has an influence on prognosis, and it has been recognised elsewhere that further work is required to determine the impact of cancer and other comorbidities on ICU outcomes [6].

The challenge facing ICU physicians is to identify which cancer patients are likely to benefit from ICU care and in which patients the expected outcome is unacceptable to justify the burdens of ICU. With an enhanced understanding of what happens to cancer patients with critical illness, clinicians would be in a better position to give prognostic information regarding expected outcomes. This would facilitate open discussion and better inform patients and relatives as well as physicians when making admission decisions pertaining to cancer patients.

While there have been a number of reports on outcomes of cancer patients after admission to ICU, to our knowledge there has been no attempt to systematically review their findings and assess the quality of evidence currently available. The aim of our study was to assess mortality among cancer patients admitted to ICU by carrying out a systematic review of published studies and to synthesise the results using both a narrative synthesis and the distribution of published mortality.

\section{Methods}

We carried out a systematic review of published literature and summarised the distribution of reported mortality using preferred reporting items for systematic reviews and meta-analyses guidelines [7].

\section{Study identification and eligibility criteria}

To be included in the review, the study had to report survival outcomes in patients with known malignancy (solid tumours) who had been admitted to a critical care area, that is, intensive care (or treatment) unit. We limited the study to solid cancers as survival in haematological cancers has been associated with consistently poorer ICU survival that has varied with time.

Two electronic databases (OVID MEDLINE and EMBASE to April 2014) were searched using a combination of medical subject headings (MeSH), title and abstract keywords. The MeSH terms "neoplasm" and "critical care"/ "intensive care"/"ICU"/“critical illness" were exploded and articles containing both terms were combined. We then searched for the terms "death", "mortality", "surviv\$", "prognos\$", "hospital\$" or "outcome". Articles that featured in both searches were then limited to those human studies published in English. We excluded paediatric studies and review articles from the search.

\section{Study selection and data extraction}

From the initial search results, a title review was performed by two separate reviewers (K.P., D.S.M.). Editorials, letters or case reports were excluded. Studies were required to report survival outcomes in patients with solid tumours admitted to ICU/critical care. Where only one reviewer felt that the title may represent an article of interest, the abstract was sought. The abstracts were then scrutinised by both reviewers before obtaining the full text of all relevant articles. Where additional potential studies were identified by hand-searching or expert recommendation, they were reviewed for eligibility in the same way as studies identified from electronic databases.

Studies were excluded if the study population entirely pre-dated 1 January 2000, if outcomes were reported for solid tumours mixed with haematological tumours, or if the study reported outcomes from a study population that had already been included in another study. This date was chosen to ensure data were contemporaneous with current ICU management practices [8-10].

Data describing the study population were collected from each paper. Several studies only reported the average age and severity of illness scores for a mixed cohort of patients with solid and haematological tumours and did not differentiate patients with solid tumours. We did not place any restrictions on these studies. Reported survival data were collected, which was most commonly ICU mortality, hospital mortality, 6-month mortality and 1-year mortality. The authors were contacted for additional information when clarification was required.

STROBE criteria were used to examine what was reported in each study including study design, variables, data sources, participants, descriptive data and outcome data [11].

\section{Distribution of mortality estimates}

ICU and hospital mortality with exact $95 \%$ confidence intervals (CIs) were calculated for each study. The 
distribution of mortality rates was examined and summarised using the Freeman-Tukey double arcsine transformation to estimate the average of the mortality distribution with $95 \%$ CIs. Random-effects estimates were used to take account of heterogeneity between studies.

Consistency between study outcomes was assessed using the Chi square test for homogeneity. The extent of variation between study outcomes was measured using the $I^{2}$ statistic. This indicates the proportion of the total variation across study outcomes attributable to heterogeneity. Values greater than $50 \%$ suggest substantial heterogeneity.

Regression and stratified analyses were used to examine the role of selected study-level characteristics (for example, location, setting and severity) in contributing to differences between study outcomes. There was insufficient study information to generate informative results from multivariable meta-regression and only univariable analyses were performed. All statistical analyses were performed using Stata v.13.1 (Stata, College Station, TX, USA).

\section{Results}

Electronic database searches identified 668 references to April 2014 of which 48 papers were included in the final selection. The studies broadly fell into two groups: those reporting on a mixture of solid cancers together, and those reporting on specific tumour types. Details of the selection processes are described in Fig. 1.

\section{Study characteristics}

We identified 48 studies that reported mortality (including short-term ICU or in-hospital mortality) for patients with solid tumours after admission to ICU (Table 1) [2, 1258]. While the inclusion criteria required that admissions from 2000 onward were reported, the studies spanned admissions between 1997 and 2011. Where cancer sitespecific outcomes were reported, the commonest (20 studies) were for lung cancers. Four papers each reported head and neck and colorectal cancers; oesophageal, breast and pancreatic cancers were each reported in three papers; stomach and gynaecological cancers each had two papers; and single papers were identified for upper gastrointestinal, all gastrointestinal, urological, prostate and melanomas. Soares et al. has published several outcome studies on a cohort of patients from May 2000 variously to December 2004 [59], to December 2005 [60], and to January 2004 [47, 61], and we chose the single most comprehensive of these papers [47].

The mean age of patients, where given, ranged from 47 to 75 years and, unless tumours were sex-specific,

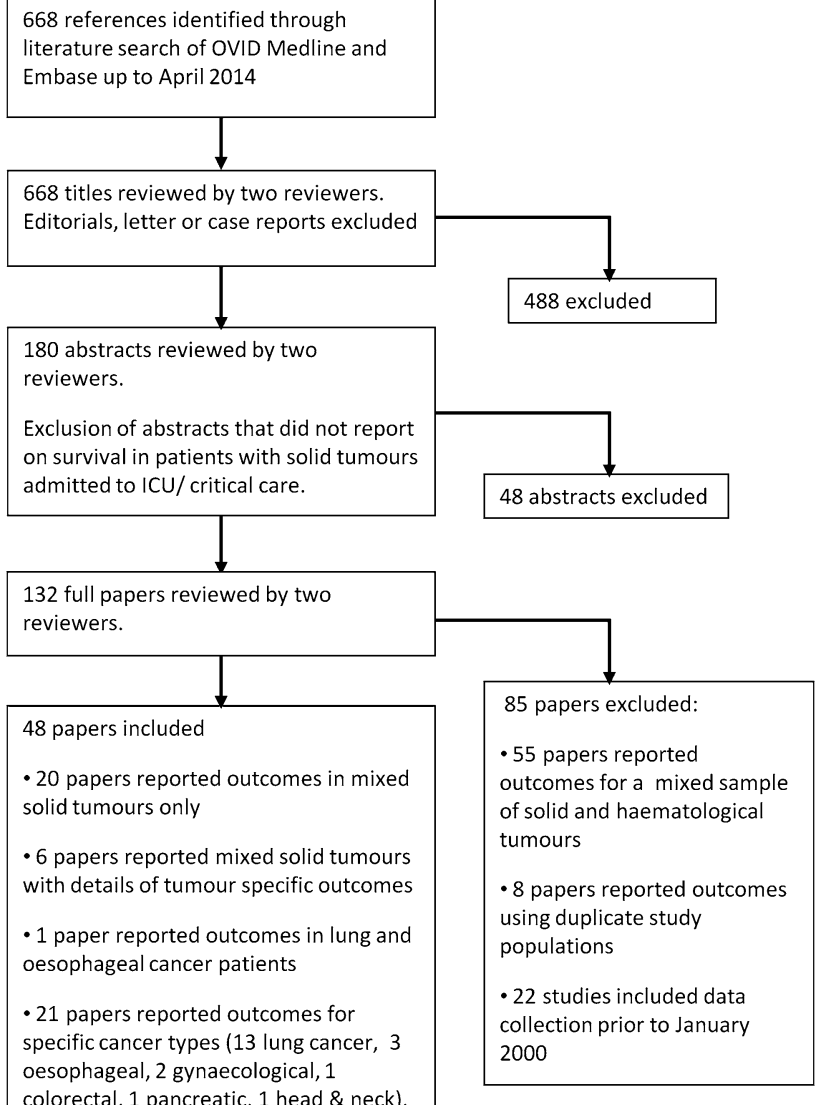

Fig. 1 Flowchart of study selection

patients comprised a mixture of men and women. Where the presence of metastatic disease was reported, this ranged from $0-100 \%$. Twenty-two studies were from Europe, ten were from Brazil and nine from North America. Slatore's study was the largest [46], with 49,373 patients whilst Azoulay et al., Darmon et al., and Song et al. reported on all cancer patients of which solid tumours made up 10,12 and 13 patients, respectively [16] [25] [52]. The majority of the studies $(36 / 48,75 \%)$ included a measure of physiological status, and there was wide variation between them; 20 studies provided mean SAPS II scores, ranging from 25.1 to 63.4 , and 15 studies gave mean APACHE II scores, ranging from 10.3 to 25.6.

We considered bias in each of the studies, using information reported under PRISMA criteria. With respect to information or measurement biases, it is possible that studies misclassified whether or not patients had cancer, or misclassified the site of the primary tumour. However, because no additional sources of information were available to validate the classification, we were unable to evaluate the extent, if any, of such biases. As all studies reported total and not cause-specific mortality, misclassification of outcomes is unlikely, although the timing of death may have been incorrect. Mortality could 


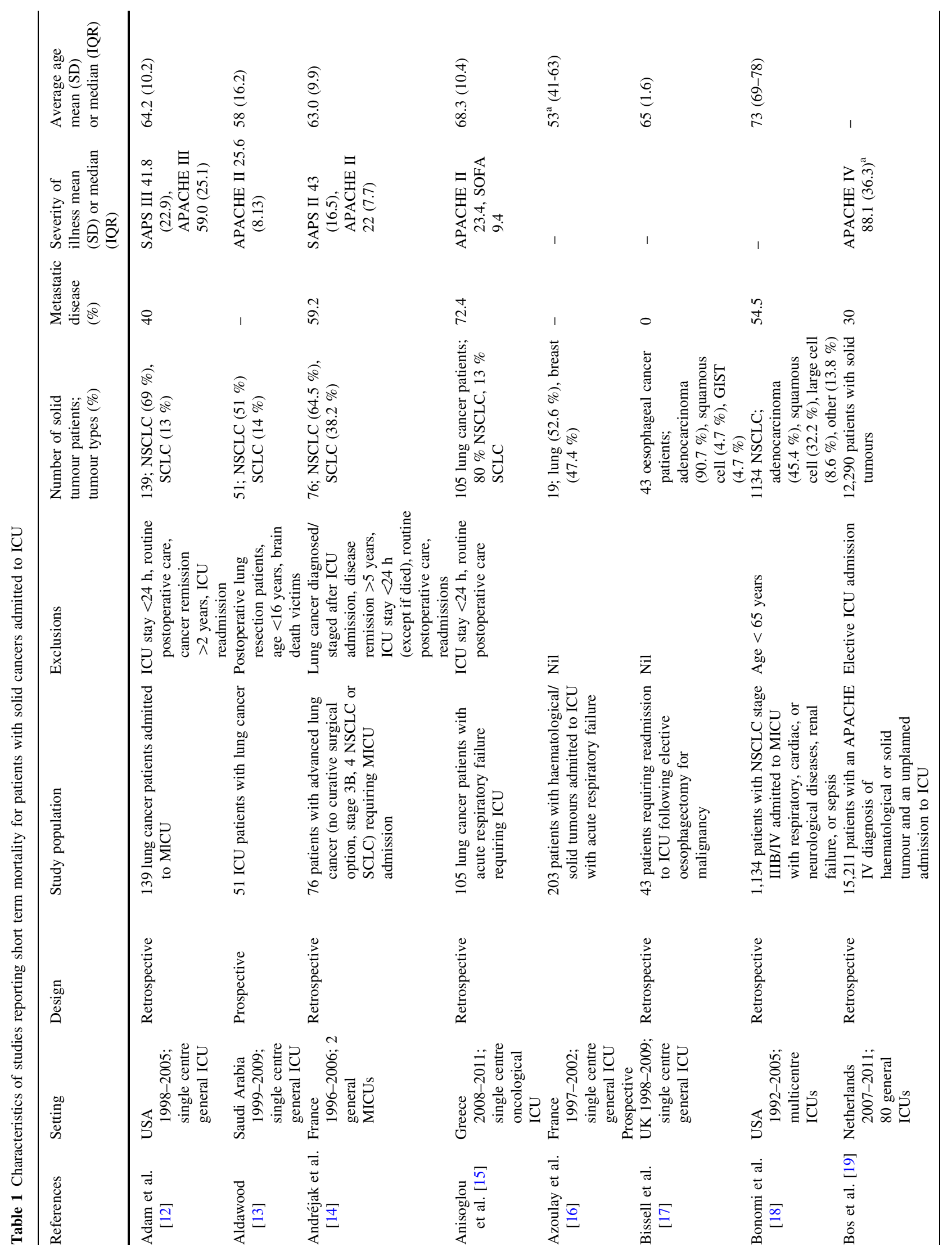




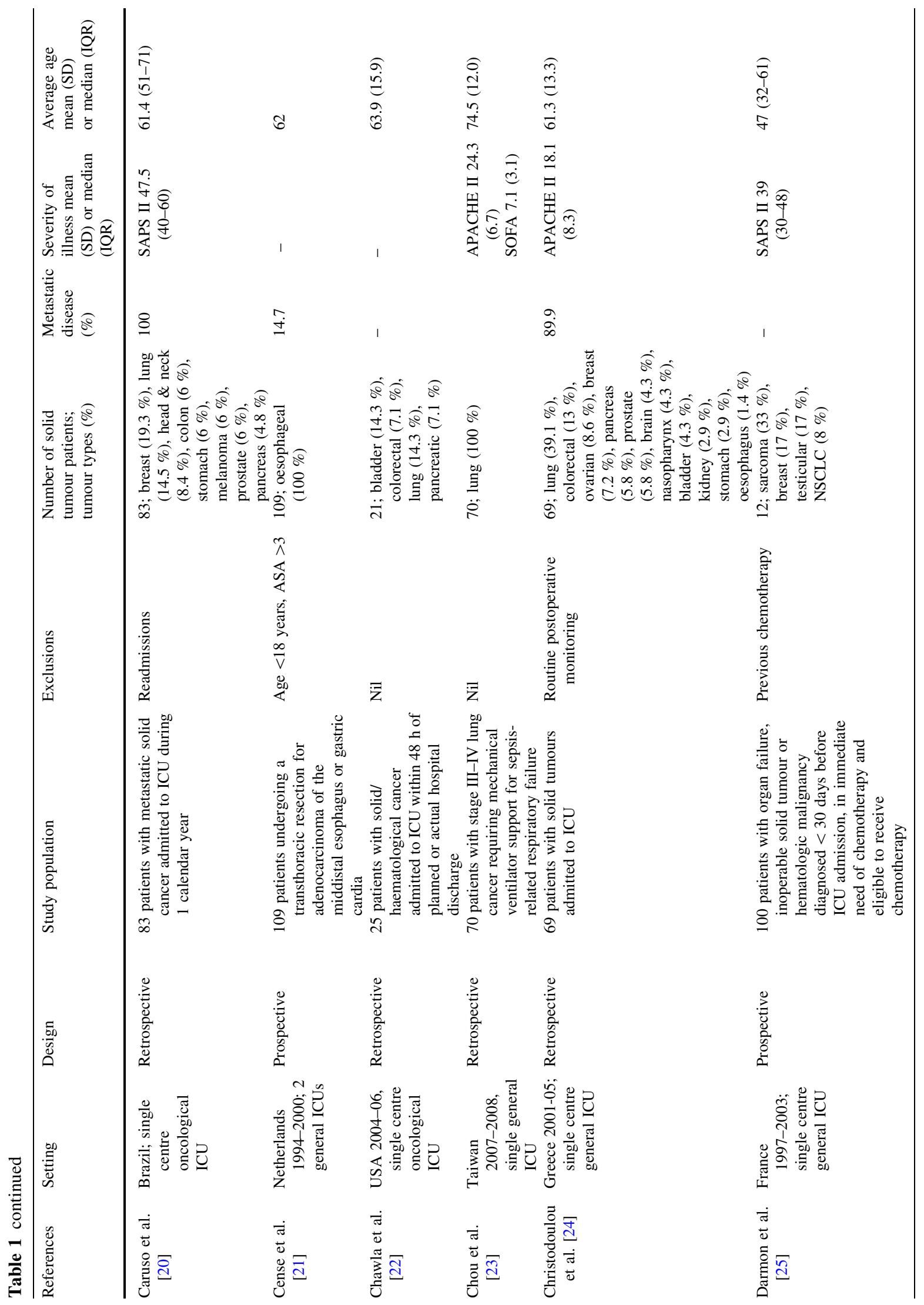




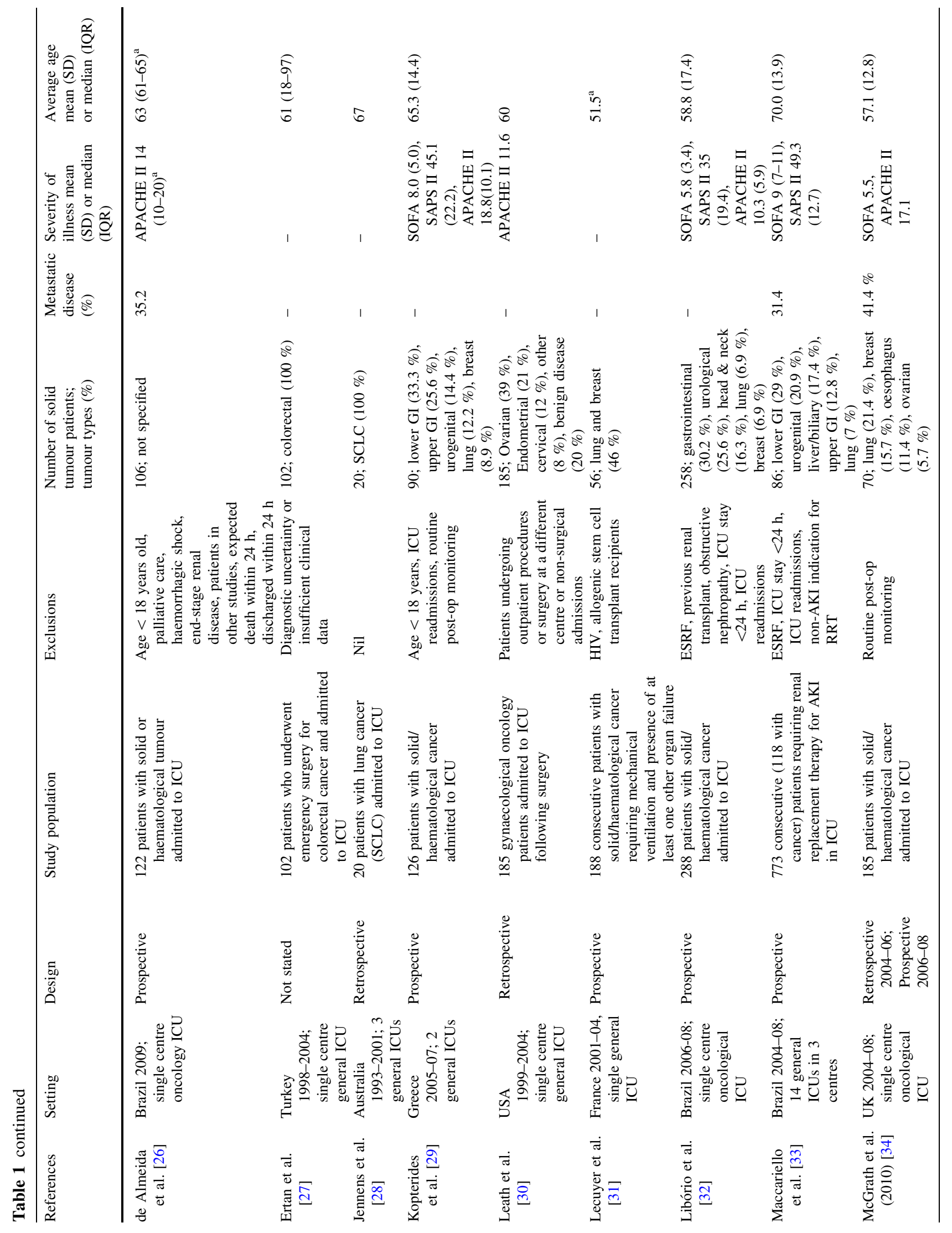




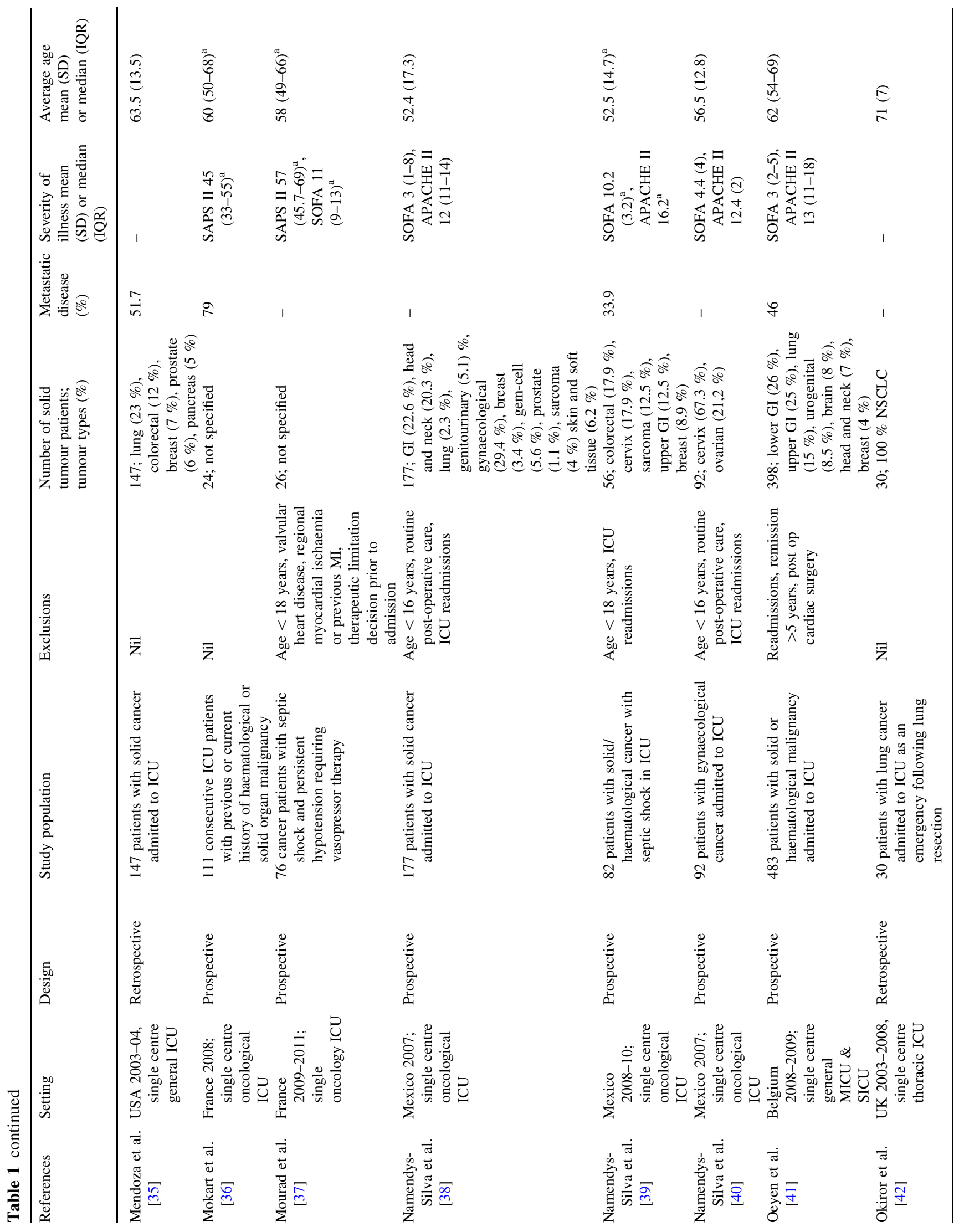




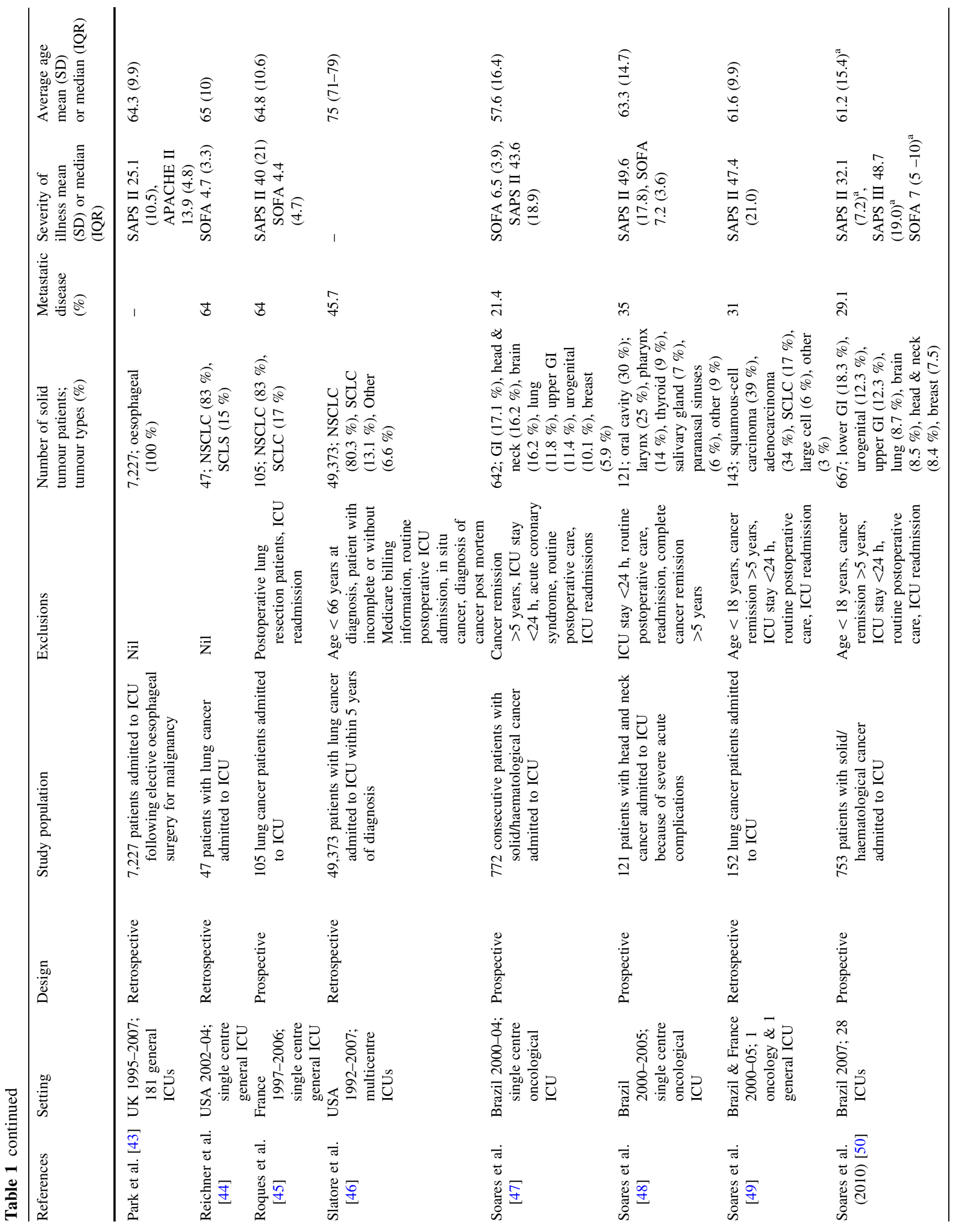




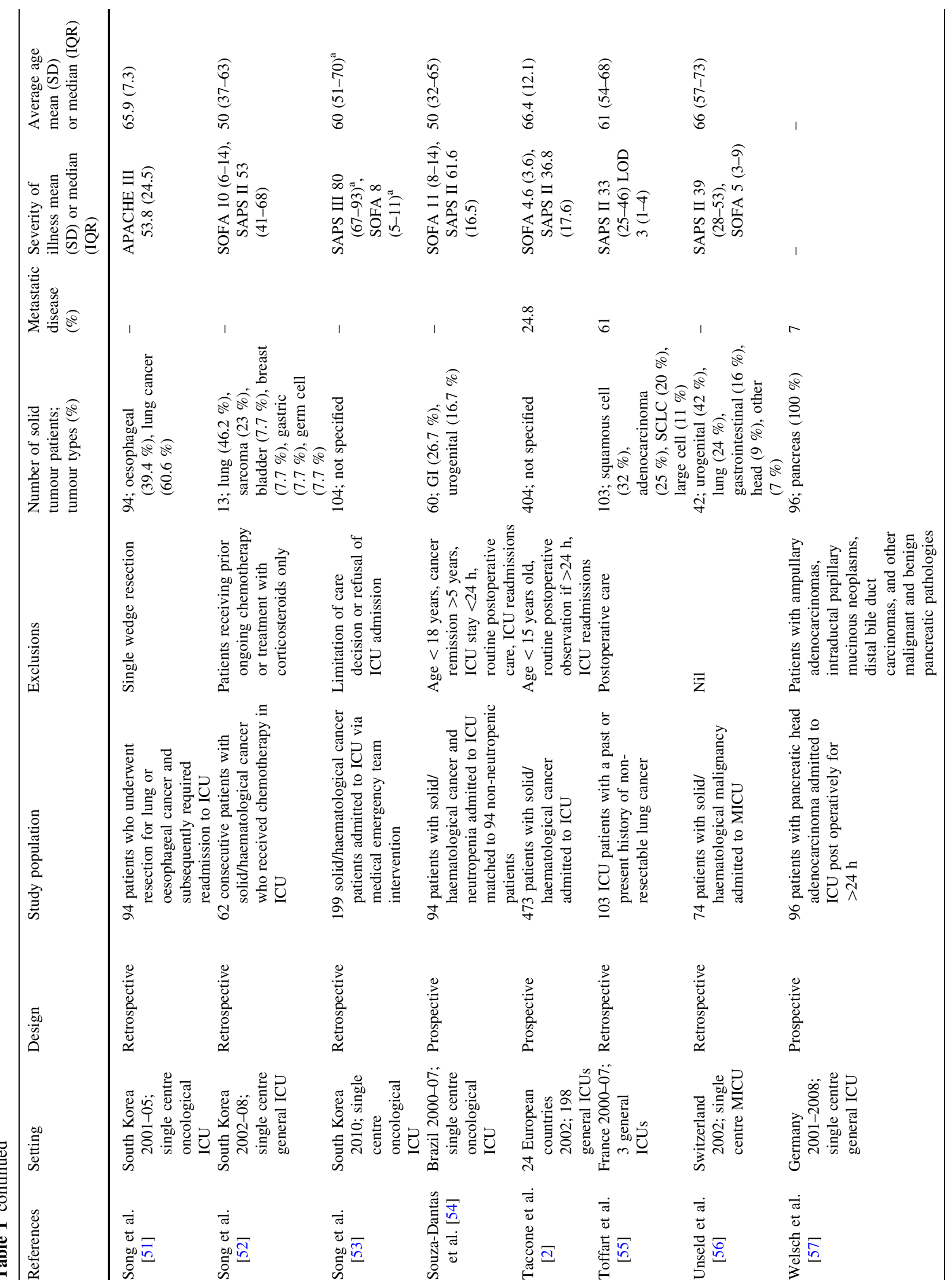




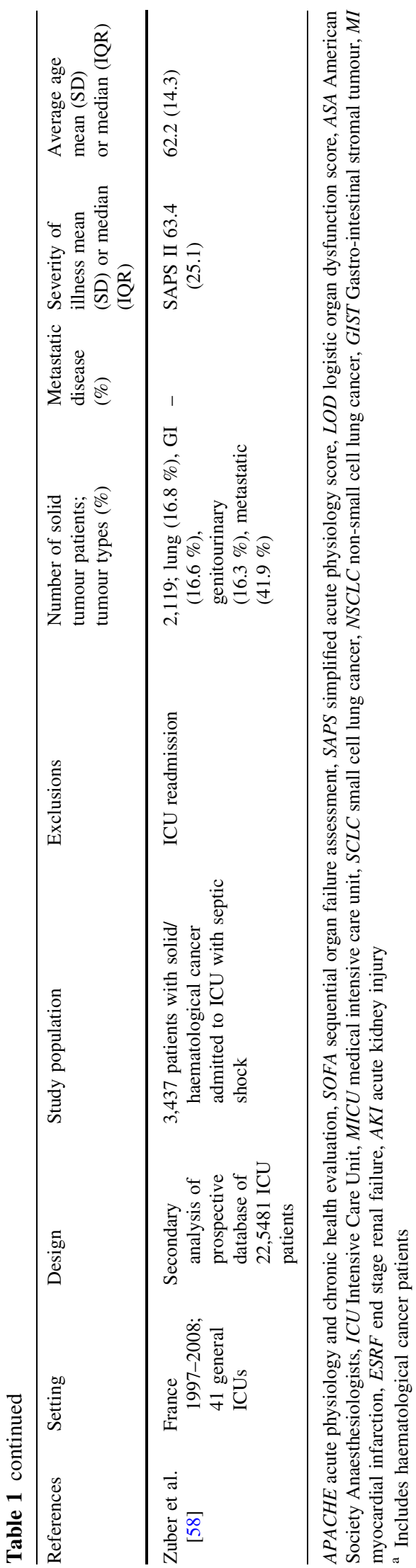

be misrepresented in those studies that excluded routine postoperative patients, patients with ICU stays of less than $24 \mathrm{~h}$, readmissions or only inclusion of patients requiring specific interventions, such as renal replacement therapy or mechanical ventilation.

Overall mortality up to 5 years after ICU admission

Mortality was reported for ICU, hospital and up to 5 years after ICU admission [Table 1, Electronic Supplementary Material (ESM)]. ICU mortality was reported in 35 studies and ranged widely from 4.5 to $85 \%$. Hospital mortality was reported in 31 studies ranging from 4.6 to $76.8 \%$. Mortality at 1 year was reported in five studies and ranged from 35.9 to $88.0 \%$, and a single study by Bissell reported $62.8 \%$ survival at 5 years [17]. ICU and hospital mortality are plotted showing the average of the distribution of rates in Fig. 2. The average mortality summarises only those studies using independent samples, so that where several papers reported on the same group of patients, only one representative paper was used. The overall average mortality within ICU was $31.2 \%$ (95\% CI 24.0-39.0\%) based on a total sample of 25,339 patients with a solid tumour, of which Bos's study comprised nearly half of the patients. There was substantial variation between studies in the proportion of patients who died in ICU $\left(I^{2}=99.1 \%, \chi^{2}=3,483, d f=31\right.$, $p<0.001)$. The average hospital mortality was $38.2 \%$ (33.8-42.7\%) among a total sample of 74,061 patients with solid tumours, of which Slatore's study comprised two-thirds of the patients. There was substantial variation in hospital mortality between studies $\left(I^{2}=98.8 \%\right.$, $\left.\chi^{2}=1,829, p<0.001\right)$. ESM Fig. 1 provides summary average mortality estimates at all follow-up periods.

\section{Predictors of survival}

When the effects of risk factors associated with survival in multivariable analyses were reported these have been described in Table 2. Severity of illness scores were generally associated with greater risks of mortality with each unit increase; the relatively larger effect size reported by Song et al. [52] reflects the comparison between patients with SOFA scores of $\leq 10$ and $>10$. The relationship between higher severity of illness score and increased mortality was reported up to 90 days after admission and was of a similar magnitude to its effect on shorter-term mortality. This may suggest that it imposes little additional risk after the initial ICU admission period.

Cancer patients who are admitted as medical, as opposed to surgical admissions had increased risk of ICU mortality of between two- and fourfold, and increased risks of in-hospital mortality of between six- and eightfold. WHO Performance Status, which is used to quantify 
Author, year, location, sample size

Adam et al (2008), USA, (139) Aldawood et al (2010), Saudi Arabia, (51) Andréjak et al (2011), France, (76) Anisoglou et al (2013), Greece, (105) Azoulay et al (2004), France, (19) Bissell et al (2013), UK, (43) Bonomi et al (2012), USA, (1134) Bos et al (2012), Netherlands, (12314) Caruso et al (2009), Brazil, (83) Chawla et al (2009), USA, (21) Chou et al (2012), Taiwan, (70) Christodoulou et al (2007), Greece, (69) Darmon et al (2005), France, (12) de Almedia et al (2012), Brazil, (106) Jennens et al (2002), Australia, (20) Kopterides et al (2011), Greece, (90) Leath et al (2006), USA, (185)

Lecuyer et al (2007), France, (56) Libório et al (2011), Brazil, (258) Maccariello et al (2010), Brazil, (86) McGrath et al (2010), UK, (70) Mendoza et al (2008), USA, (147) Mourad et al (2014), France, (72) Namendys-Silva et al (2011), Mexico, (56) Namendys-Silva et al (2010), Mexico, (177) Oeyen et al (2012), Belgium, (398) Okiror et al (2012), UK, (30) Park et al (2009), UK, (7227) Reichner et al (2006), USA, (47) Roques et al (2009), France, (105) Slatore et al (2012), USA, (49373) Soares et al (2005), Brazil, (642) Soares et al (2010), Brazil, (667) Song et al (2007), South Korea, (94) Song et al (2011), South Korea, (13) Song et al (2012), South Korea, (104) Souza-Dante et al (2011), Brazil, (60) Taccone et al (2009), Europe, (404) Toffart et al (2011), France, (103) Unseld et al (2013), Switzerland, (42) Welch et al (2010), Germany, (540) Zuber et al (2012), France, (2119) Average mortality
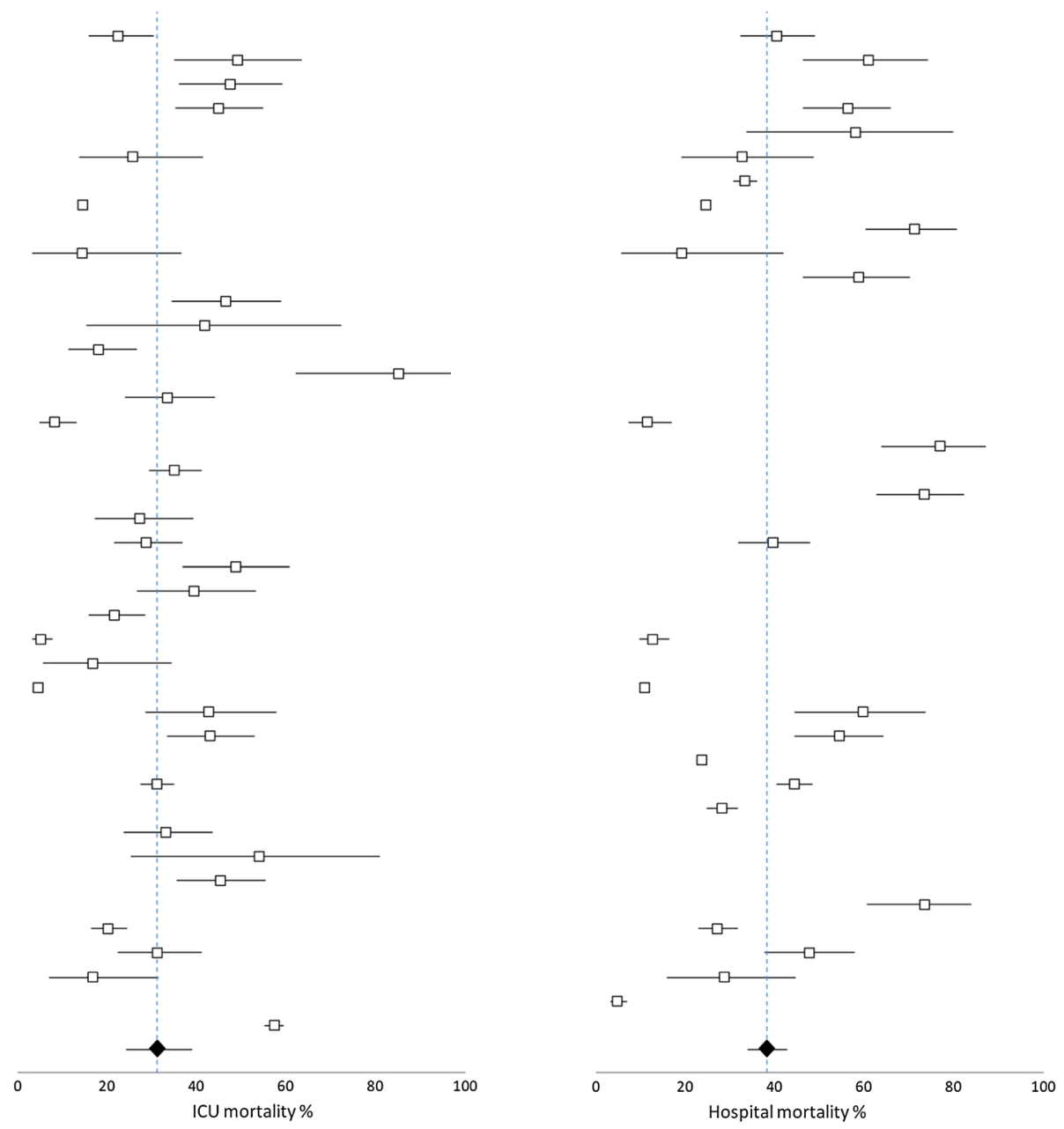

Fig. 2 ICU and hospital mortality among ICU patients with solid tumours

cancer patients' general health and functioning, was associated with survival. Generally, papers compared patients with scores of 3 and 4 (from capable of only limited self-care to completely disabled and confined to bed or chair) with those of 0,1 and 2 ; where alternative thresholds were used, these have been indicated in Table 2. Poorer performance status was associated with increased ICU mortality of between four- and sevenfold, and increased mortality by two- to threefold at 90 days after ICU admission. Sepsis increased ICU mortality by fivefold and in-hospital mortality between two- and fivefold. Mechanical ventilation increased ICU mortality by around sixfold in most studies; Mourad's much higher figure of nearly 17-fold increased ICU mortality included haematological patients and the confidence interval around the estimate was wide [37]. Use of vasopressors increased the risks of both ICU and in-hospital mortality. The increased mortality at 30 days reported by Darmon is of a similar magnitude to that reported in ICU by several authors, and again this may suggest that its effects are not sustained beyond ICU [25].

The impact of cancer stage has been inconsistently associated with mortality. Mendoza's study of 147 patients with mixed solid tumours found metastatic disease to be independently predictive of hospital mortality on multivariate analysis [35]. Soares' study of patients with head and neck cancer identified that those with stage IV disease had a higher risk of in-hospital death with OR 3.8 (95\% CI 1.28-11.28) [62]. A further study by Soares of cancer patients receiving $>24 \mathrm{~h}$ of invasive mechanical ventilation found that hospital mortality was associated with recurrence/progression of cancer status (OR 3.43, $95 \%$ CI 1.81-6.53 compared with controlled cancer) and airway/pulmonary involvement by the tumour as the reason for ventilation (OR 5.73 CI 1.92-17.08) [61]. However, an additional three papers did not find an association between metastatic disease and short-term outcomes such as ICU or hospital mortality [2, 24, 33]. 


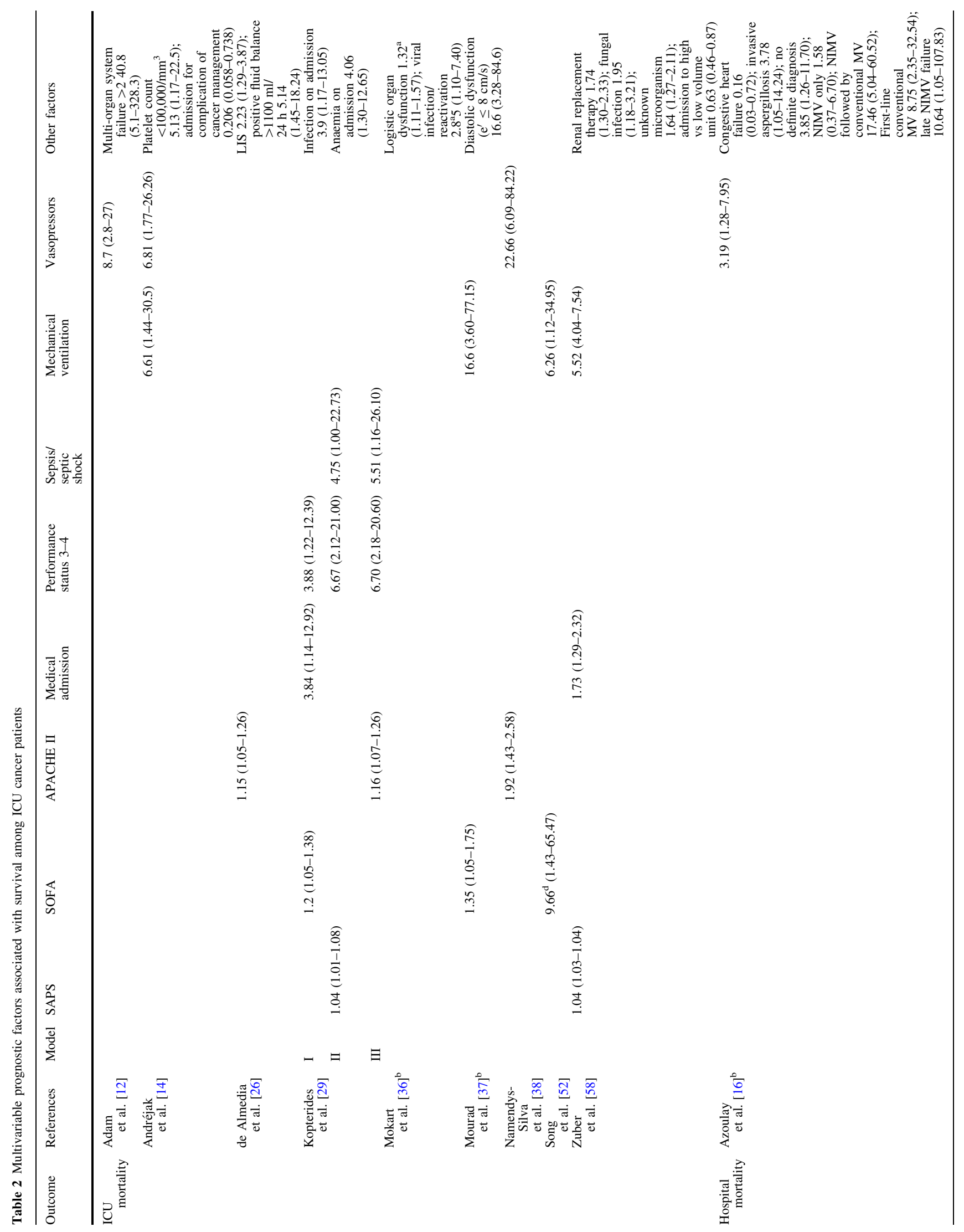




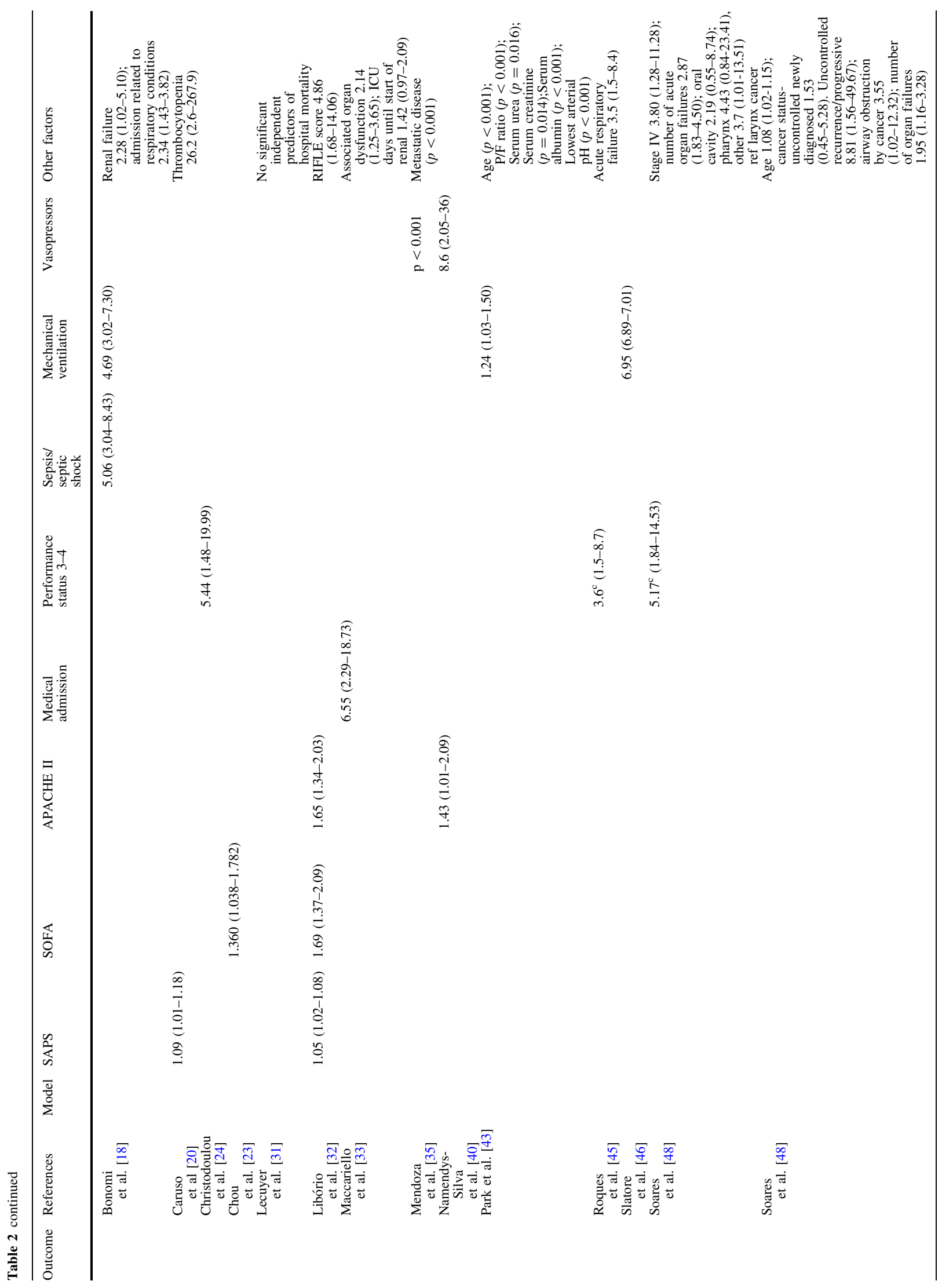




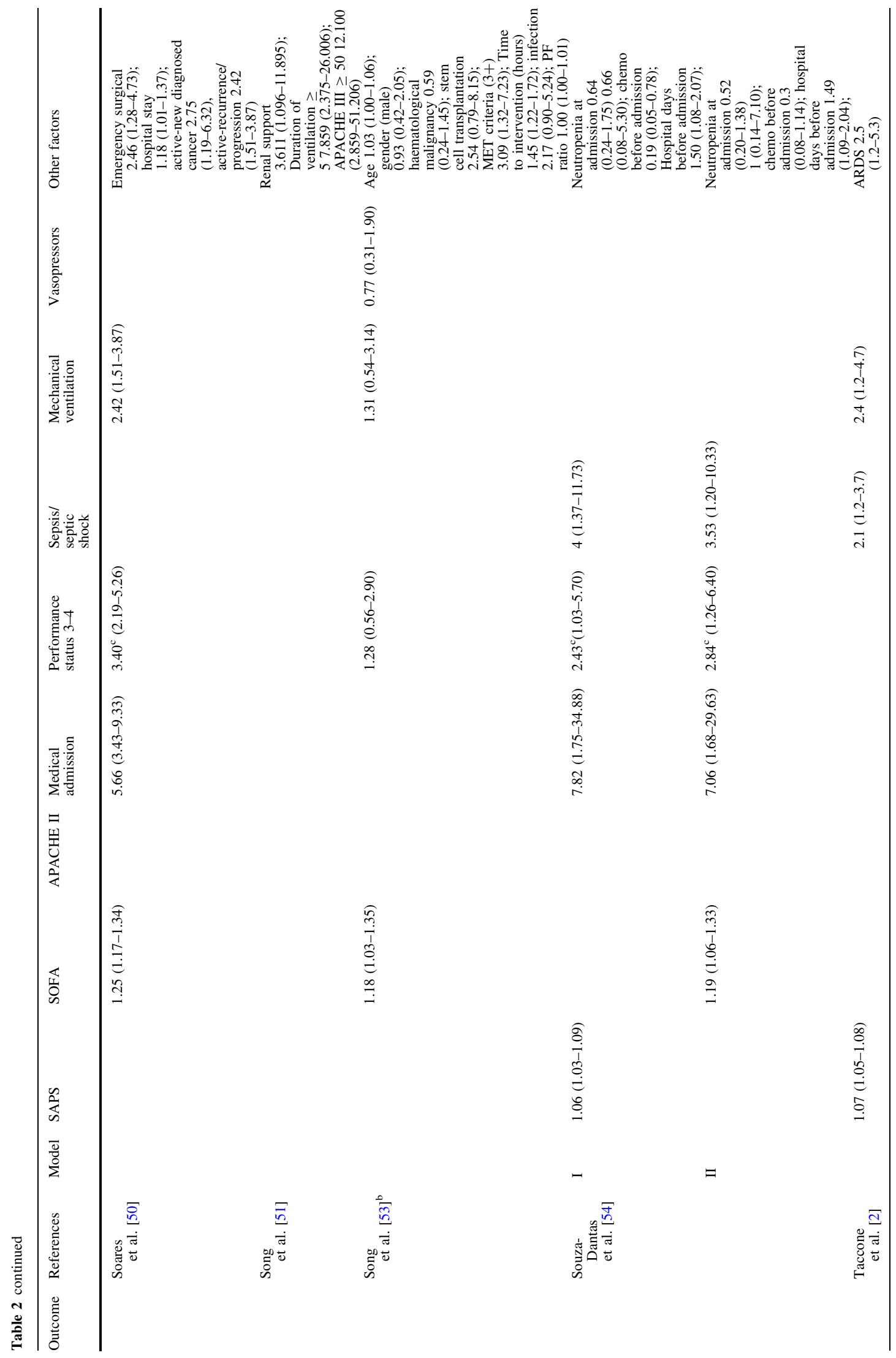




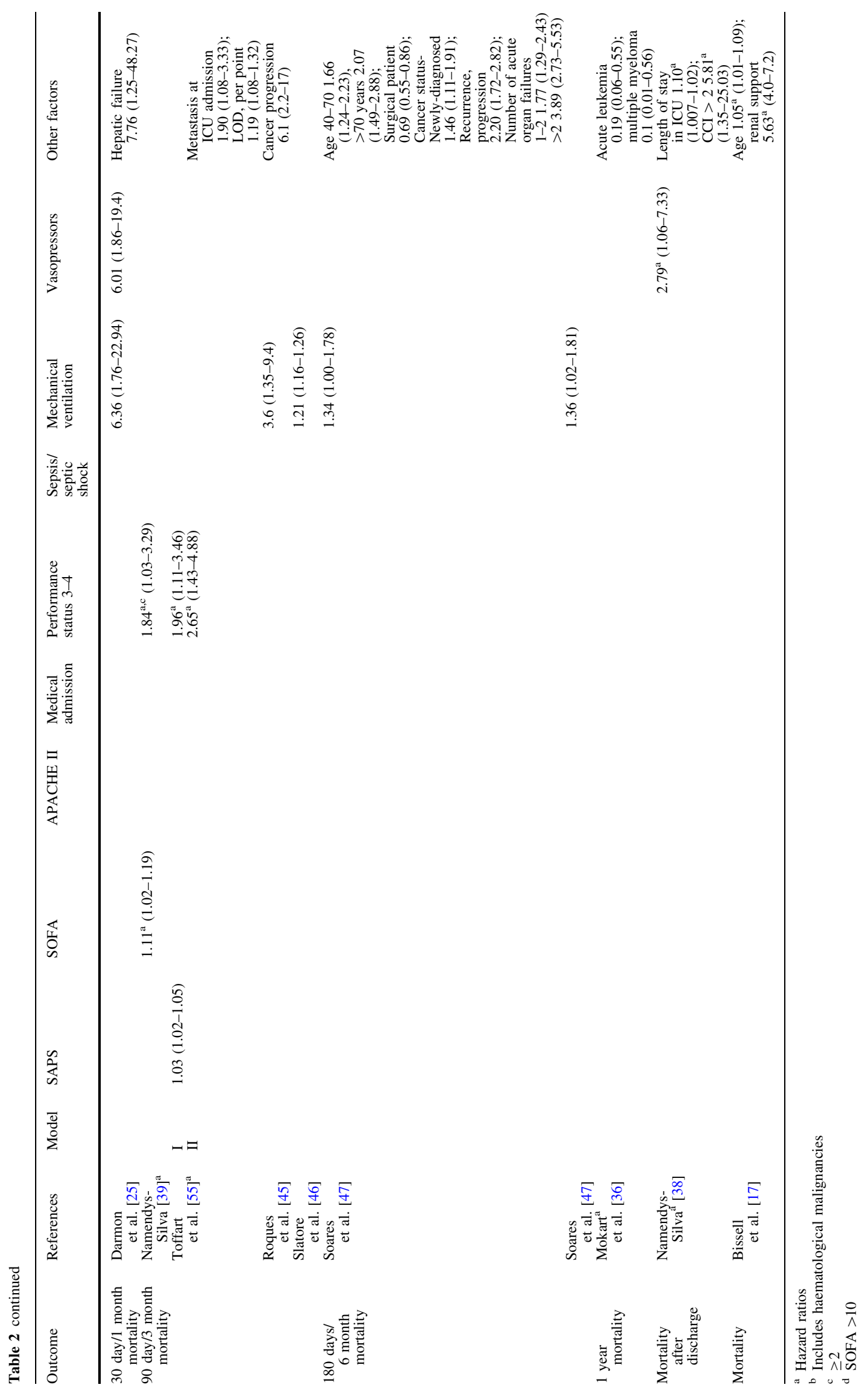


The impact of leukopenia and neutropenia has been assessed in many of the studies and was not found to be associated with short-term mortality [2, 25, 29, 32, 54].

Studies varied widely in their mean acute illness scores (Table 1) and reported mortality (ESM Table 1). Generally, studies with higher acute illness score reported higher ICU mortality (ESM Fig.2). However, there was some variation in mortality between studies with similar acute illness scores, and these reflect differences in other patient characteristics, particularly cancer site.

ICU and hospital mortality for specific tumour sites

Figure 3 summarises short-term mortality where this has been described for specific tumour sites, indicating the sitespecific average and overall average (additional data are provided in ESM Table 2). It is apparent from Fig. 3 that survival varies between studies on the same cancer site and between different cancer sites. Precision of estimates varied considerably between studies. Generally, mortality was highest for patients with lung cancers and lowest for patients with gynaecological cancers (average ICU mortality $40.1 \%, 95 \%$ CI 28.6-52.2 and $12.0 \%, 95 \%$ CI 7.4-10.4, respectively). Other individual tumours were less frequently reported with four papers reporting outcomes for colorectal cancer (average hospital mortality $35.0 \%$ ), four papers in head and neck tumours (average hospital mortality $54.7 \%$ ), three papers for oesophageal malignancy (average hospital mortality $19.9 \%$ ) and four papers for breast cancer (average hospital mortality $57.7 \%$ ).

\section{Discussion}

This systematic literature review identified a set of studies that describe contemporary outcomes in non-haematological cancer patients after admission to ICU. The 48 papers that reported on solid cancers were characterised by a wide range of case-mix variables both in terms of critical illness and in tumour types. The broad range of observed outcomes, with ICU mortality ranging from 4.5 to $85 \%$, reflects the heterogeneity of patients described in
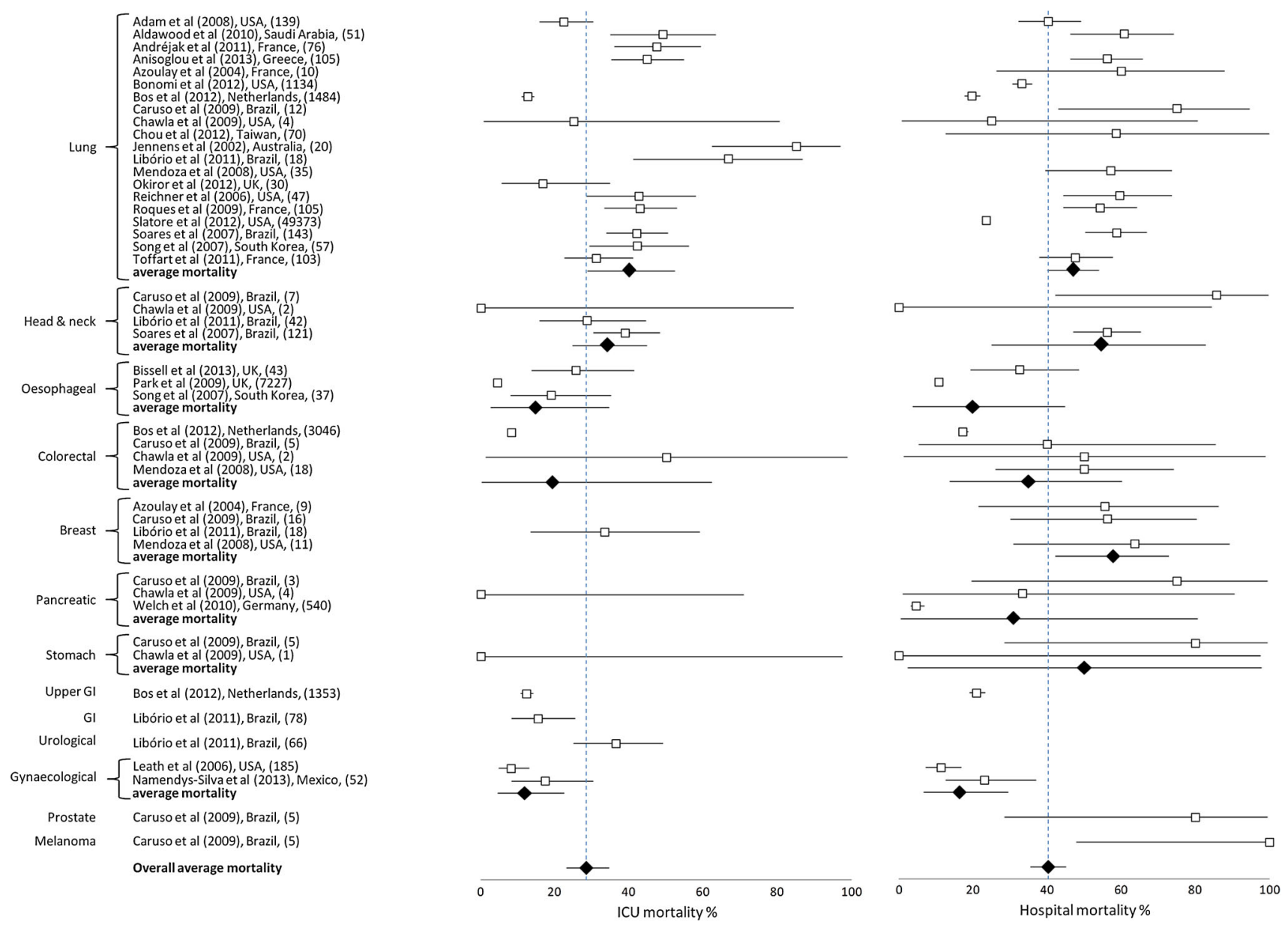

Fig. 3 ICU and hospital mortality among ICU patients with specific tumours 
the available literature. However, average mortality across all included studies with ICU mortality of $31.2 \%$ and hospital mortality of $38.2 \%$ is considerably lower than that which has been historically reported. Cancer patients should therefore not be excluded from ICU exclusively based on having an underlying malignancy, and instead those factors known to be associated with survival should be taken into account.

A number of studies looked at factors associated with survival. Poorer physiological status was associated with poorer ICU and hospital survival, but the range of different scoring systems employed, and the absence of any measure from some studies, makes summary estimates difficult in this patient group. All types of organ failure were associated with a poorer outcome; however, of these, requirement for invasive mechanical ventilation had the strongest effect on mortality. In addition, poor chronic health or limited functional status have been demonstrated to be associated with poorer survival. These findings are consistent with those seen in the general ICU population and are not specific to cancer patients. Whilst tumour type has not been demonstrated to be associated with mortality in any of the individual studies, the average mortality by tumour types described in this systematic review suggests that there is variation. The impact of disease stage and presence of metastasis has been inconsistently associated with mortality and the exact role these factors play is uncertain. Thus, despite around $15 \%$ of ICU admissions being for patients with known malignancies [2], current literature is unable to predict likely survival of the individual cancer patient after ICU admission; however, it can guide prognostication.

Our study has strengths and weaknesses. It is the first systematic review on outcomes among cancer patients admitted to ICU. We have used established systematic review procedures, PRISMA guidelines [7], and STROBE criteria for assessing observational studies [11]. Unlike narrative reviews, our study has a specific, explicit and therefore reproducible methodological strategy for identifying and synthesising relevant papers and is not based on the subjectivity of the authors. Our analysis adds to current literature by consolidating and summarising a large amount of information from primary published sources which many busy practicing ICU clinicians would not have time to identify or read. As such, its strength lies in pooling this information in an accessible form while highlighting the paucity and heterogeneity of information available on specific cancer outcomes.

The principal weakness of our study is that we have included all studies within this field whether the focus was on the general ICU cancer population or a subgroup such as those with sepsis, a specific organ failure or an individual tumour type. As a result, there are large differences between the study populations of the included papers which is reflected in the distribution of mortality rates that they report. The differences in terms of patient population, type of cancer, or type of patients (surgical vs. non-surgical) are confounding biases and contribute towards the heterogeneity we report. There are vast differences in the outcomes associated with surgical admissions versus medical admissions to ICU, and this effect seems to be exaggerated within the oncological population. For example, the three studies with the lowest mortality [30, 41, 43] includes mainly elective surgical patients. In contrast, the studies with higher mortality [20,31, 33, 54] includes only a few surgical patients, and instead selected patients based on their severity (mechanical ventilation plus at least one organ failure) [31]: only patients requiring renal replacement therapy [33], the extent of the underlying disease [20] or both. The difference in reported mortality is therefore to be expected.

Bos et al. [19] noted that many studies which report on prognostic factors mainly involve specialised oncological ICUs, making it difficult to extrapolate to general ICUs where the mixture of tumour types and expertise is different. They suggested that their own study was most appropriately compared to papers by Taconne et al. and Soares et al. [2, 50]. But even in this limited comparison, there were important differences in terms of study size, duration, and discrimination of emergency admissions, medical and surgical patients. Given the paucity and variability of the published literature, we felt that it would have been even less informative to have further restricted our inclusion criteria as this would have lost more than half of the published data with no increase in precision. This is important because, although we have summarised the distribution of reported mortality using the average mortality with $95 \%$ confidence intervals, the mortality reference range of published studies is justifiably very wide.

As the incident number of cancers will continue to increase globally [63], driven largely by aging populations but in some countries by increased exposures to risk factors, demand for ICU support for cancer patients and for information to guide admission policies will also rise. Our work adds to current literature because it draws together different strands of international research and highlights the ways in which these studies of cancer patients in ICU differ. We feel that current evidence on outcomes of cancer patients after admission to ICU would be improved with additional clinical details such as treatment intent, cancer staging/histology or pre-ICU clinical pathways. Targets for future research should build upon the work that has already been published by reporting outcomes in clearly defined groups and producing further prognostic information on those factors that are associated with poorer survival.

Whilst oncological ICUs provide a large patient population in which to study these patients, they may not be representative of the general ICU cancer population and therefore additional studies require to be performed on both groups. Where patients are admitted to general ICUs, there is a value in reporting comparative outcomes for non-cancer patients to allow calculation of the additional risk posed by 
having cancer. In addition to describing survival over the short, medium and longer terms, research is needed to describe whether cancer patients are likely to receive planned anti-cancer therapy after discharge from ICU, as admissions are currently assumed to be suitable for ongoing treatment following successful discharge. Because there are international variations in the definition of ICUs and in the case-mix of patients they treat, it will be important for future research to clearly define staffing levels, interventions provided, and patient characteristics, so that results can be usefully generalised [64].

Conflicts of interest All authors declare no conflicts of interest.

\section{References}

1. Coleman MP, Rachet B, Woods LM, Mitry E, Riga M, Cooper N, Quinn MJ, Brenner H, Esteve J (2004) Trends and socioeconomic inequalities in cancer survival in England and Wales up to 2001. Br J Cancer 90:1367-1373. doi: 10.1038/sj.bjc. 6601696

2. Taccone FS, Artigas AA, Sprung CL, Moreno R, Sakr Y, Vincent JL (2009) Characteristics and outcomes of cancer patients in European ICUs. Crit Care 13:R15. doi:10.1186/cc7713

3. Griffiths J, Fortune G, Barber V, Young JD (2007) The prevalence of post traumatic stress disorder in survivors of ICU treatment: a systematic review. Intensive Care Med 33:1506-1518. doi: 10.1007/s00134-007-0730-z

4. Clark D (2002) Between hope and acceptance: the medicalisation of dying. Br Med J 324:1391-1391

5. Garrouste-Orgeas M, Montuclard L, Timsit JF, Reignier J, Desmettre T, Karoubi P, Moreau D, Montesino L, Duguet A, Boussat S, Ede C, Monseau Y, Paule T, Misset B, Carlet J (2005) Predictors of intensive care unit refusal in French intensive care units: a multicentre study. Crit Care Med 33:750-755

6. Esper AM, Martin GS (2011) The impact of comorbid [corrected] conditions on critical illness. Crit Care Med 39:2728-2735. doi: 10.1097/CCM.0b013e318236f27e

7. Moher D, Liberati A, Tetzlaff J, Altman DG, Group P (2009) Preferred reporting items for systematic reviews and metaanalyses: the PRISMA statement. BMJ 339:b2535. doi:10.1136/bmj.b2535

8. Brower RG, Matthay MA, Morris A et al (2000) Ventilation with lower tidal volumes as compared with traditional tidal volumes for acute lung injury and the acute respiratory distress syndrome. N Engl J Med 342:1301-1308

9. Kress JP, Pohlman AS, O'Connor MF, Hall JB (2000) Daily interruption of sedative infusions in critically ill patients undergoing mechanical ventilation. N Engl J Med 342:1471-1477. doi:10.1056/NEJM 200005183422002
10. Rivers E, Nguyen B, Havstad S, Ressler J, Muzzin A, Knoblich B, Peterson E, Tomlanovich M, Early Goal-Directed Therapy Collaborative Group (2001) Early goal-directed therapy in the treatment of severe sepsis and septic shock. N Engl J Med 345:1368-1377. doi:10.1056/NEJMoa010307

11. Strengthening the Reporting of Observational studies in Epidemiology (2007). STROBE checklist. http://www.strobe-statement.org/ index.php?id=available-checklists Accessed 9 Feb 2014

12. Adam AK, Soubani AO (2008) Outcome and prognostic factors of lung cancer patients admitted to the medical intensive care unit. Eur Respir J 31:47-53. doi: 10.1183/09031936.00031607

13. Aldawood AS (2010) Prognosis and resuscitation status of critically ill patients with lung cancer admitted to the intensive care unit. Anaesth Intensive Care 38:920-923

14. Andrejak C, Terzi N, Thielen S, Bergot E, Zalcman G, Charbonneau P, Jounieaux V (2011) Admission of advanced lung cancer patients to intensive care unit: a retrospective study of 76 patients. BMC Cancer 11:159. doi:10.1186/1471-2407-11-159

15. Anisoglou S, Asteriou C, Barbetakis N, Kakolyris S, Anastasiadou G, Pnevmatikos I (2013) Outcome of lung cancer patients admitted to the intensive care unit with acute respiratory failure. Hippokratia 17:60-63

16. Azoulay E, Thiery G, Chevret S, Moreau D, Darmon M, Bergeron A, Yang K, Meignin V, Ciroldi M, Le Gall JR, Tazi A, Schlemmer B (2004) The prognosis of acute respiratory failure in critically ill cancer patients. Medicine (Baltimore) 83:360-370

17. Bissell L, Khan OA, Mercer SJ, Somers SS, Toh SK (2013) Long term outcomes following emergency intensive care readmission after elective oesophagectomy. Acta Chir Belg 113:14-18
18. Bonomi MR, Smith CB, Mhango G, Wisnivesky JP (2012) Outcomes of elderly patients with stage IIIB-IV nonsmall cell lung cancer admitted to the intensive care unit. Lung Cancer 77:600-604. doi: 10.1016/j.lungcan.2012.05.103

19. Bos MM, de Keizer NF, Meynaar IA, Bakhshi-Raiez F, de Jonge E (2012) Outcomes of cancer patients after unplanned admission to general intensive care units. Acta Oncol 51:897-905. doi: 10.3109/0284186X.2012.679311

20. Caruso P, Ferreira AC, Laurienzo CE, Titton LN, Terabe DS, Carnieli DS, Deheinzelin D (2010) Short- and longterm survival of patients with metastatic solid cancer admitted to the intensive care unit: prognostic factors. Eur J Cancer Care (Engl) 19:260-266. doi: 10.1111/j.1365-2354.2008.01031.x

21. Cense HA, Hulscher JB, de Boer AG, Dongelmans DA, Tilanus HW, Obertop $\mathrm{H}$, Sprangers MA, van Lanschot JJ (2006) Effects of prolonged intensive care unit stay on quality of life and long-term survival after transthoracic esophageal resection. Crit Care Med 34:354-362

22. Chawla S, Pastores SM, Hassan K, Raoof ND, Voigt LP, Alicea M, Halpern NA (2009) ICU admissions after actual or planned hospital discharge incidence, clinical characteristics, and outcomes in patients with cancer. Chest 136:1257-1262. doi: 10.1378/chest.08-2909

23. Chou KT, Chen CS, Su KC, Hung MH, Hsiao YH, Tseng CM, Chen YM, Lee YC, Perng DW (2012) Hospital outcomes for patients with stage III and IV lung cancer admitted to the intensive care unit for sepsis-related acute respiratory failure. J Palliat Med 15:1234-1239. doi: 10.1089/jpm.2012.0084

24. Christodoulou C, Rizos M, Galani E, Rellos K, Skarlos DV, Michalopoulos A (2007) Performance status (PS): a simple predictor of short-term outcome of cancer patients with solid tumors admitted to the intensive care unit (ICU). Anticancer Res 27:2945-2948 
25. Darmon M, Thiery G, Ciroldi M, de Miranda S, Galicier L, Raffoux E, Le Gall JR, Schlemmer B, Azoulay E (2005) Intensive care in patients with newly diagnosed malignancies and a need for cancer chemotherapy. Crit Care Med 33:2488-2493

26. de Almeida JP, Palomba H, Galas FRBG, Fukushima JT, Duarte FA, Nagaoka D, Torres V, Yu L, Vincent JL, Auler JOC, Hajjar LA (2012) Positive fluid balance is associated with reduced survival in critically ill patients with cancer. Acta Anaesthesiol Scand 56:712-717. doi: 10.1111/j.1399-6576.2012.02717.x

27. Ertan T, Yoldas O, Kilic YA, Kilic M, Gocmen E, Koc M, Tez M (2008) External validation of prognostic models among cancer patients undergoing emergency colorectal surgery. Am J Surg 195:439-441. doi: 10.1016/j.amjsurg.2007.03.012

28. Jennens RR, Rosenthal MA, Mitchell P, Presneill JJ (2002) Outcome of patients admitted to the intensive care unit with newly diagnosed small cell lung cancer. Lung Cancer 38:291-296

29. Kopterides P, Liberopoulos P, Ilias I, Anthi A, Pragkastis D, Tsangaris I,

Tsaknis G, Armaganidis A, Dimopoulou I (2011) General Prognostic Scores in Outcome Prediction for Cancer Patients Admitted to the Intensive Care Unit. Am J Crit Care 20:56-66. doi: 10.4037/Ajcc2011763

30. Leath CA 3rd, Kendrick JEt, Numnum TM, Straughn JM, Straughn JM Jr, Rocconi RP, Sfakianos GP, Lang JD Jr (2006) Outcomes of gynecologic oncology patients admitted to the intensive care unit following surgery: a university teaching hospital experience. Int J Gynecol Cancer 16:1766-1769. doi:10.1111/j.1525-1438.2006.00702.x

31. Lecuyer L, Chevret S, Thiery G, Darmon M, Schlemmer B, Azoulay E (2007) The ICU trial: a new admission policy for cancer patients requiring mechanical ventilation. Crit Care Med 35:808-814. doi:10.1097/01.CCM.000 0256846.27192.7A

32. Liborio AB, Abreu KL, Silva GB Jr, Lima RS, Barreto AG, Barbosa OA, Daher EF (2011) Predicting hospital mortality in critically ill cancer patients according to acute kidney injury severity. Oncology 80:160-166. doi: 10.1159/000329042
33. Maccariello E, Valente C, Nogueira L, Bonomo $\mathrm{H} \mathrm{Jr}$, Ismael $\mathrm{M}$, Machado JE, Baldotto F, Godinho M, Rocha E, Soares M (2011) Outcomes of cancer and non-cancer patients with acute kidney injury and need of renal replacement therapy admitted to general intensive care units. Nephrol Dial Transplant 26:537-543. doi: 10.1093/ndt/gfq441

34. McGrath S, Chatterjee F, Whiteley C, Ostermann M (2010) ICU and 6-month outcome of oncology patients in the intensive care unit. QJM 103:397-403. doi:10.1093/qjmed/hcq032

35. Mendoza V, Lee A, Marik PE (2008) The hospital-survival and prognostic factors of patients with solid tumors admitted to an ICU. Am J Hosp Palliat Care 25:240-243. doi: 10.1177/1049909108315523

36. Mokart D, Etienne A, Esterni B, Brun JP, Chow-Chine L, Sannini A, Faucher M, Blache JL (2012) Critically ill cancer patients in the intensive care unit: short-term outcome and 1-year mortality. Acta Anaesthesiol Scand 56:178-189. doi: 10.1111/j.1399-6576.2011.02579.x

37. Mourad M, Chow-Chine L, Faucher M, Sannini A, Brun JP, de Guibert JM, Fouche L, Lambert J, Blache JL, Mokart D (2014) Early diastolic dysfunction is associated with intensive care unit mortality in cancer patients presenting with septic shock. Br J Anaesth 112:102-109. doi: 10.1093/Bja/Aet296

38. Namendys-Silva SA, TexcocanoBecerra J, Herrera-Gomez A (2010) Prognostic factors in critically ill patients with solid tumours admitted to an oncological intensive care unit. Anaesth Intensive Care 38:317-324

39. Namendys-Silva SA, Gonzalez-Herrera MO, Texcocano-Becerra J, HerreraGomez A (2011) Clinical characteristics and outcomes of critically ill cancer patients with septic shock. QJM 104:505-511. doi: 10.1093/qjmed/hcq260

40. Namendys-Silva SA, Gonzalez-Herrera MO, Texcocano-Becerra J, HerreraGomez A (2013) Outcomes of critically ill gynecological cancer patients admitted to intensive care unit. Am J Hosp Palliat Medicine 30:7-11. doi: 10.1177/1049909112437028

41. Oeyen SG, Benoit DD, Annemans L, Depuydt PO, Van Belle SJ, Troisi RI, Noens LA, Pattyn P, Decruyenaere JM (2013) Long-term outcomes and quality of life in critically ill patients with hematological or solid malignancies: a single center study. Intensive Care Med 39:889-898. doi:10.1007/s00134012-2791-x
42. Okiror L, Patel N, Kho P, Ladas G, Dusmet M, Jordan S, Cordingley J, Lim E (2012) Predicting risk of intensive care unit admission after resection for non-small cell lung cancer: a validation study. Interact Cardiovasc Thorac Surg 14:31-33. doi:10.1093/icvts/ivr060

43. Park DP, Welch CA, Harrison DA, Palser TR, Cromwell DA, Gao F, Alderson D, Rowan KM, Perkins GD (2009) Outcomes following oesophagectomy in patients with oesophageal cancer: a secondary analysis of the ICNARC case mix programme database. Crit Care 13(Suppl 2):S1. doi:10.1186/cc7868

44. Reichner CA, Thompson JA, O'Brien S, Kuru T, Anderson ED (2006) Outcome and code status of lung cancer patients admitted to the medical ICU. Chest 130:719-723. doi: 10.1378/chest.130.3.719

45. Roques S, Parrot A, Lavole A, Ancel PY, Gounant V, Djibre M, Fartoukh M (2009) Six-month prognosis of patients with lung cancer admitted to the intensive care unit. Intensive Care Med 35:2044-2050. doi: 10.1007/s00134-009-1625-y

46. Slatore CG, Cecere LM, LeTourneau JL, O'Neil ME, Duckart JP, Wiener RS, Farjah F, Cooke CR (2012) Intensive Care Unit Outcomes Among Patients With Lung Cancer in the Surveillance, Epidemiology, and End ResultsMedicare Registry. J Clin Oncol 30:1686-1691. doi: 10.1200/Jco.2011.40.0846

47. Soares M, Salluh JI, Ferreira CG, Luiz RR, Spector N, Rocco JR (2005) Impact of two different comorbidity measures on the 6-month mortality of critically ill cancer patients. Intensive Care Med 31:408-415. doi:

10.1007/s00134-005-2554-z

48. Soares M, Salluh JI, Toscano L, Dias FL (2007) Outcomes and prognostic factors in patients with head and neck cancer and severe acute illnesses. Intensive Care Med 33:2009-2013. doi: 10.1007/s00134-007-0775-z

49. Soares M, Darmon M, Salluh JI, Ferreira CG, Thiery G, Schlemmer B, Spector N, Azoulay E (2007) Prognosis of lung cancer patients with lifethreatening complications. Chest 131:840-846. doi: 10.1378/chest.06-2244

50. Soares M, Caruso P, Silva E et al (2010) Characteristics and outcomes of patients with cancer requiring admission to intensive care units: a prospective multicentre study. Crit Care Med 38:9-15. doi:10.1097/CCM. 0b013e3181c0349e 
51. Song SW, Lee HS, Kim JH, Kim, Lee JM, Zo JI (2007) Readmission to intensive care unit after initial recovery from major thoracic oncology surgery. Ann Thorac Surg 84:1838-1846. doi: 10.1016/j.athoracsur.2007.06.074 (discussion)

52. Song JU, Suh GY, Chung MP, Kim H, Kwon OJ, Jung CW, Kang WK, Park K, Jeon K (2011) Risk factors to predict outcome in critically ill cancer patients receiving chemotherapy in the intensive care unit. Support Care Cancer 19:491-495. doi: 10.1007/s00520-010-0841-x

53. Song JU, Suh GY, Park HY, Lim SY, Han SG, Kang YR, Kwon OJ, Woo S, Jeon K (2012) Early intervention on the outcomes in critically ill cancer patients admitted to intensive care units. Intensive Care Med 38:1505-1513. doi: 10.1007/s00134-012-2594-0

54. Souza-Dantas VC, Salluh JI, Soares M (2011) Impact of neutropenia on the outcomes of critically ill patients with cancer: a matched case-control study. Ann Oncol 22:2094-2100. doi: 10.1093/annonc/mdq711

55. Toffart AC, Minet C, Raynard B, Schwebel C, Hamidfar-Roy R, Diab S, Quetant S, Moro-Sibilot D, Azoulay E, Timsit JF (2011) Use of intensive care in patients with nonresectable lung cancer. Chest 139:101-108. doi: 10.1378/chest.09-2863
56. Unseld S, Schuepbach RA, Maggiorini M (2013) ICU, hospital and one year mortality of patients suffering from solid or haematological malignancies. Swiss Med Wkly 143:w13741. doi: 10.4414/smw.2013.13741

57. Welsch T, Degrate L, Zschabitz S, Hofer S, Werner J, Schmidt J (2011) The need for extended intensive care after pancreaticoduodenectomy for pancreatic ductal adenocarcinoma. Langenbecks Arch Surg 396:353-362. doi:10.1007/s00423-010-0629-y

58. Zuber B, Tran TC, Aegerter P, Grimaldi D, Charpentier J, Guidet B, Mira JP, Pene F, Network CU-R (2012) Impact of case volume on survival of septic shock in patients with malignancies. Crit Care Med 40:55-62. doi: 10.1097/CCM.0b013e31822d74ba

59. Soares M, Salluh JI, Carvalho MS, Darmon M, Rocco JR, Spector N (2006) Prognosis of critically ill patients with cancer and acute renal dysfunction. J Clin Oncol 24:4003-4010. doi: 10.1200/JCO.2006.05.7869
60. Soares M, Salluh JI, Torres VB, Leal JV, Spector N (2008) Short- and longterm outcomes of critically ill patients with cancer and prolonged ICU length of stay. Chest 134:520-526. doi: 10.1378/chest.08-0359

61. Soares M, Salluh JI, Spector N, Rocco JR (2005) Characteristics and outcomes of cancer patients requiring mechanical ventilatory support for $>24 \mathrm{hrs}$. Crit Care Med 33:520-526

62. Soares M, Salluh JIF, Toscano L, Dias FL (2007) Outcomes and prognostic factors in patients with head and neck cancer and severe acute illnesses. Intensive Care Med 33:2009-2013. doi: 10.1007/s00134-007-0775-z

63. Curado MP, Edwards B, Shin H, Storm H, Ferlay J, Heanue M, Boyle P (2007) Cancer incidence in five continents, vol IX. IARC Scientific Publications No 160, Lyon

64. Prin M, Wunsch H (2012) International comparisons of intensive care: informing outcomes and improving standards. Curr Opin Crit Care 18:700-706. doi:10.1097/MCC.0b013e $32835914 \mathrm{~d} 5$ 